\title{
Beta-adrenoreceptor mechanisms in essential tremor: a comparative single dose study of the effect of a non-selective and a beta- 2 selective adrenoreceptor antagonist
}

\author{
LYNN CLEEVES, LESLIE J FINDLEY
}

From the MRC Neuro-Otology Unit, the National Hospital for Neurol Diseases, London and the Regional Centre for Neurology and Neurosurgery, Oldchurch Hospital, and Harold Wood Hospital, Romford, Essex, UK

SUMMARY In order to study the mode of action of beta-adrenoreceptor antagonists in essential tremor the efficacy of singe oral doses of 2,4 and $10 \mathrm{mg}$ LI 32-468, a peripherally acting, selective beta- 2 adrenoreceptor antagonist, was compared with a single oral dose of $120 \mathrm{mg}$ propranolol in a randomised, double blind, placebo controlled trial. Both the lowest dose of LI and propranolol were shown to be equally superior to placebo in attenuating tremor magnitude. This finding supports the contention that the beneficial effect of beta-adrenoreceptor antagonists in essential tremor is mediated via peripheral beta- 2 receptor mechanisms.

Essential tremor is a common monosymptomatic disorder of unknown aetiology. Betaadrenoreceptor antagnoists are considered the drugs of first choice in its treatment.' Whilst some of the behavioural characteristics of essential tremor resemble enhanced physiological tremor and it is now accepted that enhanced physiological tremor is mediated by peripheral beta- 2 mechanisms, ${ }^{2}$ there is still dispute as to the site and mode of action of beta-adrenoreceptor antagonists in the control of essential tremor.

The drug which so far has been proved to be of greatest therapeutic benefit is propranolol, ${ }^{3-6}$ a non-selective beta-adrenoreceptor antagonist which, due to its lipid solubility, readily penetrates the central nervous system. A number of clinical trials support the contention that the main effect of these drugs is mediated predominantly by peripheral beta- 2 adrenoreceptor mechanisms. ${ }^{8}$ However, intra-arterial and intra-venous studies with propranolol have implicated central effects of this drug ${ }^{9}$ and some studies have shown that the selective beta-1 adrenoreceptor antagonist metoprolol can also be effective in reducing tremor in some

Address for reprint requests: Leslie J. Findley, MRC NeuroOtology Unit, Institute of Neurology, National Hospital, Queen Sq, London, WC1N 3BG, UK. patients. ${ }^{10-15}$ Some of these studies may be criticised because at the dosages used the relative selectivity of beta-adrenoreceptor antagonists is at least partially lost, and as metoprolol is a lipid soluble drug, central and peripheral effects cannot be differentiated. In a recent study Leigh et al $^{16}$ compared the effects of atenolol, sotalol and metoprolol and found no support for the concept that central or peripheral beta-1 mechanisms are important in essential tremor and that the beneficial effect of betaadrenoreceptor antagonists may be mediated predominantly through peripheral beta- 2 adrenoreceptor mechanisms. However, from the results presented in that study atenolol, a hydrophilic, predominantly beta-1 selective adrenoreceptor antagonist, was equally effective in attenuating tremor as the non-selective adrenoreceptor antagonist sotalol on "objective" assessments. Therefore, in order to investigate further the mechanism of action of these drugs, a new agent with a highly selective effect on peripheral beta-2 adrenoreceptors is needed.

LI 32-468 (4-(3-tert-butylamino-2-hydroxypropoxy)spiro[cyclohexan-1, 2-indan]-1-on hydrogen malonate) is a freely hydrophilic, selective beta- 2 adrenoreceptor antagonist which in animal studies shows signs of effects on the central nervous system only at extremely high doses, for example, 
Table 1 Clinical details of the 12 patients used in the study

\begin{tabular}{|c|c|c|c|c|c|c|}
\hline Patient & Age (yr) & Sex & $\begin{array}{l}\text { Duration of } \\
\text { tremor }(y r)\end{array}$ & Family history & $\begin{array}{l}\text { Magnitude of } \\
\text { tremor }^{*}\end{array}$ & $\begin{array}{l}\text { Frequency of } \\
\text { tremor }(\mathrm{Hz}) \dagger\end{array}$ \\
\hline $\begin{array}{l}1 \\
2 \\
3 \\
4 \\
5 \\
6 \\
7 \\
8 \\
9 \\
10 \\
11 \\
12 \\
\text { Mean }\end{array}$ & $\begin{array}{l}50 \\
56 \\
19 \\
50 \\
72 \\
58 \\
19 \\
62 \\
56 \\
24 \\
64 \\
32 \\
46 \cdot 8\end{array}$ & $\begin{array}{l}\mathbf{F} \\
\mathbf{M} \\
\mathbf{F} \\
\mathbf{M} \\
\mathbf{M} \\
\mathbf{M} \\
\mathbf{M} \\
\mathbf{M} \\
\mathbf{M} \\
\mathbf{F} \\
\mathbf{M} \\
\mathbf{M}\end{array}$ & $\begin{array}{r}1 \\
50 \\
1 \\
4 \\
1 \\
3 \\
15 \\
2 \\
50 \\
7 \\
40 \\
17 \\
15.9\end{array}$ & $\begin{array}{l}- \\
- \\
+ \\
+ \\
- \\
+ \\
+ \\
- \\
- \\
+\end{array}$ & $\begin{array}{r}13 \cdot 0(\cdot 004) \\
46 \cdot 8(.033) \\
24 \cdot 1 \\
29 \cdot 0 \\
9 \cdot 01.013) \\
60 \cdot 2(.007) \\
56 \cdot 4(.038) \\
41 \cdot 2(.034) \\
9 \cdot 3(.005) \\
11 \cdot 6(.003) \\
21 \cdot 2(.013) \\
17 \cdot 2(.008) \\
28 \cdot 3(.017)\end{array}$ & $\begin{array}{l}9 \cdot 2 \\
5 \cdot 9 \\
6 \cdot 8 \\
6 \cdot 1 \\
5 \cdot 7 \\
6 \cdot 3 \\
6 \cdot 4 \\
6 \cdot 8 \\
7 \cdot 1 \\
9 \cdot 6 \\
6 \cdot 3 \\
7 \cdot 4\end{array}$ \\
\hline
\end{tabular}

*Magnitude of tremor in the more affected hand was calculated from the mean of five pre-treatment measurements. Magnitude is expressed both as root mean squared acceleration $\left(\mathrm{g} \times 10^{-3}\right.$, where $\left.\mathrm{g}=981 \mathrm{~cm} / \mathrm{sec}^{2}\right)$ and as hand displacement in cm (in parentheses). $\dagger$ Frequency of the dominant peak of tremor in the more affected hand was calculated from the mean of five pre-treatment measurements.

$100 \mathrm{mg} / \mathrm{kg}$ in the rat. This compound possesses high affinity for metabolic beta-adrenoreceptors which mediate glycogenolysis that is 100 times more potent than propranolol, whereas in isolated guinea pig atria it is seven times less potent than propranolol as a beta-adrenoreceptor antagonist. Its membrane stabilising activity is less than one third that of propranolol and, like propranolol, has no intrinsic sympathomimetic activity. ${ }^{17}$ In human volunteer studies, a single dose of 2 mg LI 32-468 elicited virtually no cardiac beta-adrenoreceptor blockade (predominantly beta-1), whereas a maximal metabolic beta-adrenoreceptor blocking effect (beta-2) was demonstrated. ${ }^{18}$

In the present study single doses of 2,4 and $10 \mathrm{mg}$ LI 32-468 were compared with $120 \mathrm{mg}$ propranolol in a double blind, placebo controlled design in patients with essential tremor.

\section{Patients and methods}

Twelve patients with essential tremor gave their informed consent to participate in the study. Relevant clinical details are presented in table 1 . The diagnosis was established on the basis of clinical history and detailed general and neurological examination, accompanied by ancillary laboratory investigations. Serum triodothyronine and thyroxine were within normal limits in all cases. None of the patients was taking other medication at the time of the study. Patients with a history of excessive alcohol consumption, congestive cardiac failure, heart block and asthma were excluded from the study. Eleven of the patients had type 2 essential tremor according to the classification proposed by Marsden et al $^{19}$ and one patient was classified as type 1 in that the tremor frequency was readily "resettable" by external perturbation of the limb from a torque motor producing displacements no greater than the amplitude of the ongoing tremor.

\section{Protocol}

The study was double blind and placebo controlled. Each patient was studied on five different occasions, separated by at least one week. Tests were performed in the morning after a light breakfast. The patients were instructed to abstain from smoking and from taking alcohol or caffeinated beverages for at least 12 hours before testing.

After 15 minutes rest, piezo-resistive linear accelerometers (Endevco 7625-10) were attached with adhesive tape, their sensitive axes orientated in the vertical plane, to the dorsal surface of each hand in the second interspace one $\mathrm{cm}$ proximal to the metacarpophalangeal joints. The devices weighed $6 \mathrm{gm}$ and had a frequency response extending from steady state acceleration to 300 $\mathrm{Hz}$ with a sensitivity of $50 \mathrm{mV} / \mathrm{g}(\mathrm{g}=$ acceleration of gravity). Hand tremor was assessed with the patient seated, fully relaxed and looking directly ahead. The forearms were supported up to the wrist and the hands were unsupported and outstretched horizontally in pronated posture during the recording. Three separate tremor recordings of about 1 min duration were obtained at $5 \mathrm{~min}$ intervals and, to minimise the possible effects of fatigue, the hands were allowed to rest freely between recordings. Accelerometric signals were amplified and recorded simultaneously on paper and magnetic tape for subsequent analysis.

On completion of tremor recording measurements of pulse rate were obtained following a 10 minute period of rest in the supine position and repeated after 1,2 and 3 minutes of standing. At this stage the patients received a single oral dose of either LI 32-468 (2 mg, $4 \mathrm{mg}$ or $10 \mathrm{mg}$ ), propranolol $120 \mathrm{mg}$ or placebo, together with $50 \mathrm{ml}$ of plain water. The dose of propranolol selected was that which has been previously shown to be superior to placebo in reducing the amplitude of essential tremor when given as a single dose. ${ }^{15}$ The lowest dose of LI used has been shown to be devoid of cardiac beta-adrenoceptor blocking activity (that is, a selective beta- 2 receptor antagonist). ${ }^{18}$ The order of treatment was randomised.

Tremor recordings and measurements of supine and standing pulse rates were repeated 2 hours after drug administration, when the plasma levels of both drugs were expected to be approaching maximum. 
Tremor analysis was performed on-line using a Hewlett Packard 5420A signal analyser. ${ }^{20}$ For each condition, that is, before and after treatment, the program averaged 150 auto-spectra each derived from overlapping 10.24 second samples of tremor. Fifty samples were taken from the beginning of each of the three separate recording periods and approximately 45 seconds of tremor recording contributed to the analysis in each period. The advantage of "overlap" analysis is that it compensates for the reduced contribution of the beginning and the end of the data sample which results from the application of a Hanning window. The spectra, averaged thus, were displayed for measurement in the form of "auto-spectra" in which the root mean square (rms) magnitude of the frequency components was plotted as a function of frequency. For simple characterisation of the tremor, measurements were taken of the frequency $(\mathrm{Hz})$ of the dominant peak and of its amplitude scaled in rms acceleration, the unit of acceleration being taken as $1 \mathrm{~g}\left(\mathrm{~g}=981 \mathrm{~cm} / \mathrm{s}^{2}\right)$. As it was found that the peak tremor frequency did not vary significantly either between recordings before and after treatment, or on the different days of assessment, the magnitude of acceleration is proportional to the amplitude of hand displacement. Thus amplitude of displacement $=([$ acceleration $\times 981] / 4$ $\times \mathrm{Pi}^{2} \times$ frequency $^{2}$ ) cm rms.

In each patient only the data obtained from the more affected hand was used for the computation of the results. In this study the dominant hand, in terms of magnitude of tremor, remained invariant in individual patients over the successive days of recording.

At the end of each recording session a $10 \mathrm{ml}$ venous blood sample was taken. Plasma LI 32-468 levels were measured by radio receptor assay according to Rosenthaler and Munzer ${ }^{21}$ and plasma levels of propranolol by gas chromatography. ${ }^{22}$ At the end of testing all patients were asked to report side effects and were specifically questioned on the occurrence of nausea, headache, dizziness, drowsiness and visual symptoms.

Changes in tremor magnitude (absolute and percentage) and frequency were evaluated by means of analysis of variance for repeated measures. Pairwise comparisons of treatments were made using the Newman-Keuls test. Pulse rate data were analysed using Student's $t$ test for related samples. In addition, relevant variables were correlated by means of the product-moment correlation coefficient.

\section{Results}

\section{Tremor frequency}

The frequency of the dominant peak of hand tremor in the patients included in the study ranged from 5.7 to $9.6 \mathrm{~Hz}$. In any single patient the frequency was similar in all pre-drug recordings and did not change significantly after the administration of either of the drugs or placebo.

\section{Tremor magnitude}

Magnitudes of tremor recorded prior to drug administration showed considerable variation between patients (range 5.8 to $102.7 \mathrm{~g} \times 10^{-3}$ ) and within patients on different days of recording. However, within any single recording session there was little fluctuation in tremor magnitude.

Table 2 presents the number of patients showing decreases, increases or no change (arbitrarily defined as a change of less than 15\%) in tremor magnitude following placebo and drug treatments. Drug effects in individual patients are presented graphically in fig 1 . Mean decreases in tremor magnitude were $9.6 \%$ after placebo, $42.4 \%$ after $2 \mathrm{mg}$ LI, $16.4 \%$ after $4 \mathrm{mg} \mathrm{LI}, 30.7 \%$ after $10 \mathrm{mg} \mathrm{LI}$ and $39.4 \%$ after propranolol (fig 2). Analysis of variance indicated a significant effect of treatments on tremor magnitude expressed either as absolute change $(p<$ $0.04)$ or percentage change $(p<0.05)$. Propranolol and $2 \mathrm{mg} \mathrm{LI}$ produced a significantly greater reduction in tremor magnitude than that produced by placebo $(p<0.05)$. The effects of propranolol and 2 mg LI were not significantly different. Neither the 4 $\mathrm{mg} \mathrm{LI}$ nor $10 \mathrm{mg}$ LI doses differed significantly in their effect from placebo.

There was a significant postive correlation between baseline magnitude of tremor and reduction in tremor magnitude for both propranolol and $2 \mathrm{mg}$ LI (absolute change $p<0.01$, percentage change $p$ $<0.05)$. There was no significant correlation between reduction in tremor magnitude and age, duration of symptoms, and tremor frequency.

\section{Pulse rate}

There was no significant difference in the pulse rate recorded after 1,2 , and 3 minutes of standing in each patient. The means of the three values was therefore taken for further calculations. Pre drug values of supine and standing pulse rate did not differ significantly between treatments.

Significant decreases in standing tachycardia were

Table 2 Numbers of patients showing decreases, increases or no change in tremor magnitude following placebo and drug treatments.

\begin{tabular}{llllll}
\hline & Placebo & $2 \mathrm{mg} \mathrm{LI}$ & $4 \mathrm{mg} \mathrm{LI}$ & $10 \mathrm{mg}$ LI & Propranolol \\
\hline $\begin{array}{l}\text { Patients showing decreases in } \\
\text { tremor }\end{array}$ & 4 & 8 & 7 & 10 & 11 \\
$\begin{array}{l}\text { Patients showing increases in } \\
\text { tremor }\end{array}$ & 2 & 1 & 2 & 1 & 1 \\
$\begin{array}{l}\text { Patients showing no change } \\
\text { 6 }\end{array}$ & 3 & 3 & 1 & 0 \\
\hline
\end{tabular}




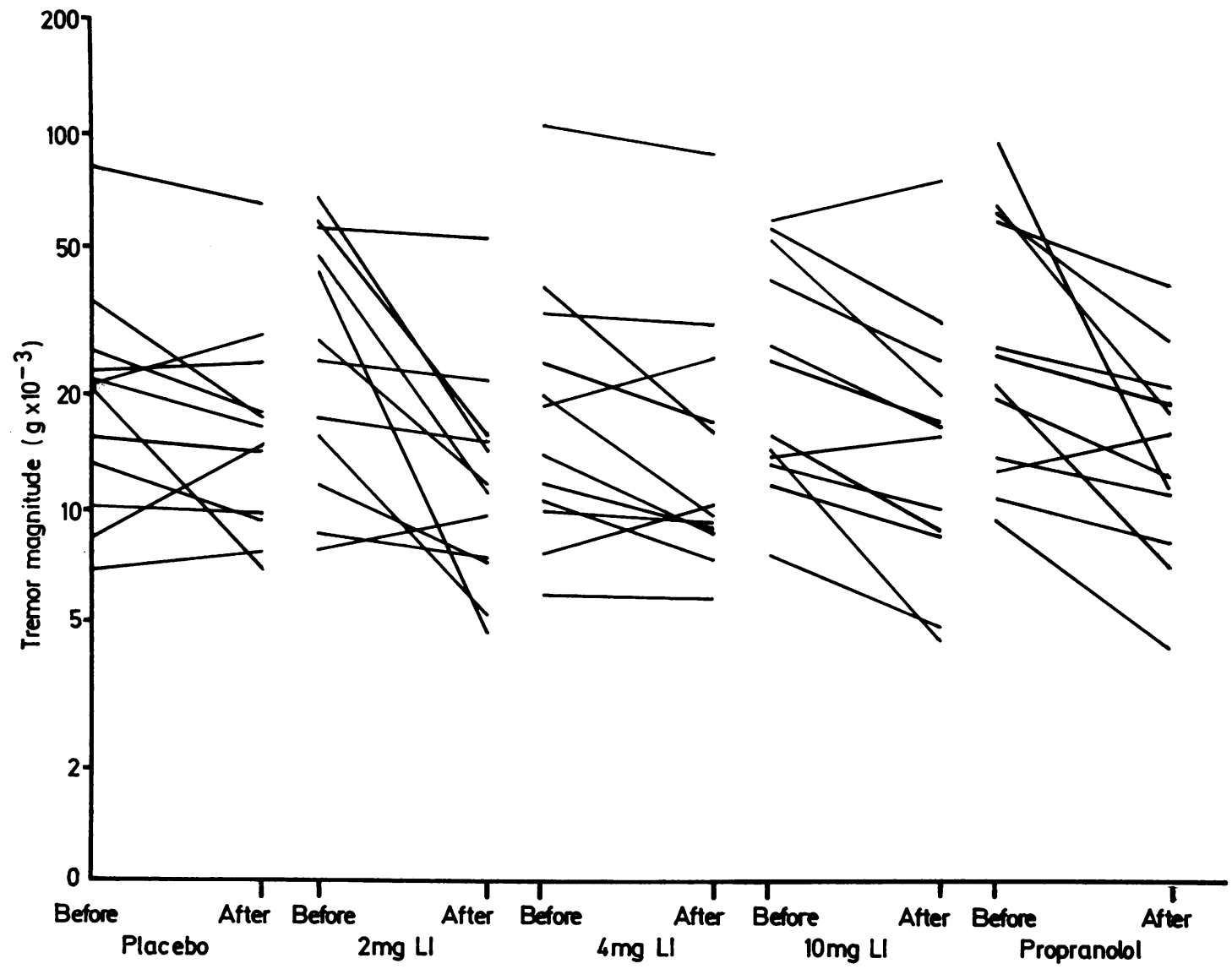

Fig 1 Values of tremor magnitude (in $\mathrm{g} \times 10^{-3}$ ) for individual patients before and after placebo and single oral doses of 2 ,



observed after administration of propranolol ( $p<$ $0.01), 4 \mathrm{mg} \mathrm{LI}$ and $10 \mathrm{mg} \mathrm{LI}(\mathrm{p}<0.05)$. Both placebo and $2 \mathrm{mg} \mathrm{Li}$ were without effect. The reduction in standing tachycardia produced by propranolol was significantly greater than that produced by $4 \mathrm{mg}$ LI but was not significantly different from $10 \mathrm{mg} \mathrm{LI}$ (fig 3).

There was no significant correlation between reduction in tremor magnitude and inhibition of standing tachycardia following the administration of propranolol or any dose of LI.

\section{Plasma drug levels}

Blood plasma levels for individual patients approximately 2 hours after single oral doses of 2 $\mathrm{mg}, 4 \mathrm{mg}$ and $10 \mathrm{mg} \mathrm{LI} 32-468$ and $120 \mathrm{mg}$ propranolol are shown in table 3 . There was no correlation between drug levels and reduction in tremor magnitude.
Side effects

None of the patients complained of any adverse reactions after any of the doses of LI or propranolol.

\section{Discussion}

The present study clearly demonstrates that a single oral dose of $2 \mathrm{mg} \mathrm{LI} 32-468$ is significantly better than placebo in reducing the magnitude of essential tremor. The mean reduction in tremor magnitude of $42 \%$ of baseline value was equipotent with the effect of $120 \mathrm{mg}$ propranolol. Single doses of $4 \mathrm{mg}$ and $10 \mathrm{mg} \mathrm{LI}$ did not have a significantly greater effect on tremor magnitude than placebo. The explanation for this is not clear. It is apparent from the results on the inhibition of standing tachycardia (fig 3) that at the $4 \mathrm{mg}$ and $10 \mathrm{mg}$ doses there has been some loss of beta- 2 selectivity. This in itself would not explain loss of tremorlytic activity as pro- 


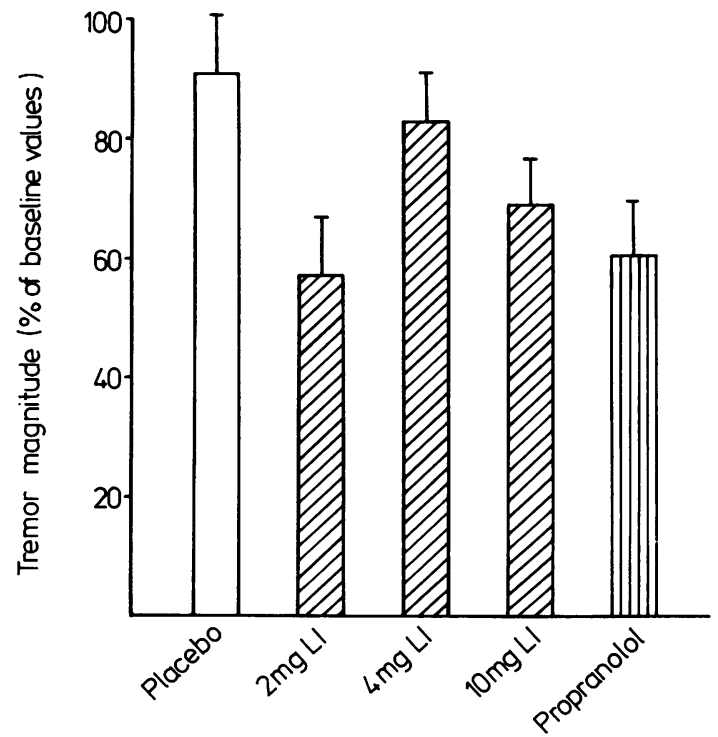

Fig 2 Mean (+ 1 SEM) values of tremor magnitude (percent of baseline value) for 12 patients after placebo and single oral doses of 2, 4 and $10 \mathrm{mg} \mathrm{LI} \mathrm{32-468} \mathrm{and} 120 \mathrm{mg}$ propranolol. Reduction in tremor magnitude was significant ( $p<0.05)$ as compared with placebo for $2 \mathrm{mg} \mathrm{LI}$ and propranolol only.

pranolol itself is a non-selective beta adrenoreceptor antagonist. One possible explanation would be the development of intrinsic sympathomimetic acivity at higher doses, though there is no evidence of this from extensive animal studies ${ }^{17}$ and the limited

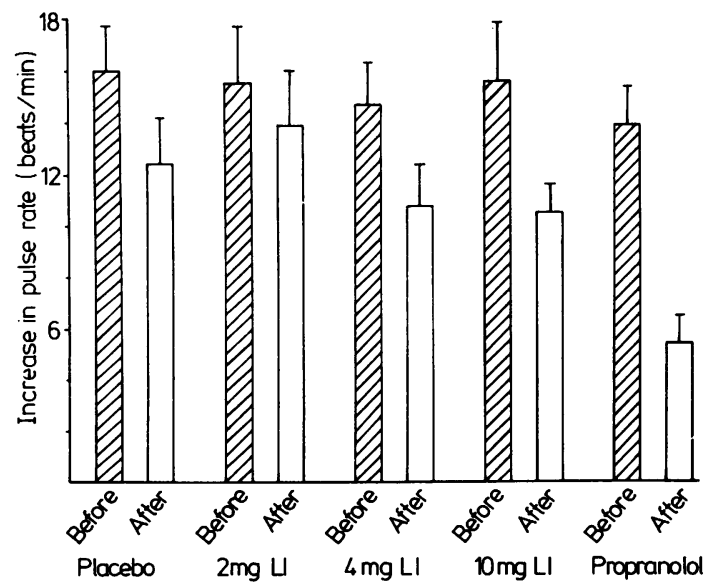

Fig 3 Mean (+ 1 SEM) increase in pulse rate on standing in 12 patients before (cross hatched) and after (open bars) treatments. Significant inhibition of standing tachycardia was observed after propranolol $(p<0.01), 4 \mathrm{mg}$ and $10 \mathrm{mg}$ $L I(p<0.05)$ as compared to values before treatment.
Table 3 Levels of LI 32-468 and propranolol in plasma (ng-equiv./ml) after a single oral dose.

\begin{tabular}{|c|c|c|c|c|}
\hline \multirow{2}{*}{ Patient } & \multicolumn{2}{|c|}{ Dose of $L I$} & \multicolumn{2}{|c|}{ Propranolol } \\
\hline & $2 \mathrm{mg}$ & $4 \mathrm{mg}$ & $10 \mathrm{mg}$ & $120 \mathrm{mg}$ \\
\hline $\begin{array}{c}1 \\
2 \\
3 \\
4 \\
5 \\
6 \\
7 \\
8 \\
9 \\
10 \\
11 \\
12 \\
\text { Mean } \\
\text { SEM }\end{array}$ & $\begin{array}{c}16.8 \\
18.3 \\
\overline{17.9} \\
11.0 \\
17.0 \\
\overline{11.0} \\
9.6 \\
16.7 \\
11.9 \\
15.7 \\
14.6 \\
1.0\end{array}$ & $\begin{array}{r}59.9 \\
54.7 \\
54.2 \\
-18.8 \\
40.0 \\
29.7 \\
22.0 \\
15.2 \\
12.1 \\
43.9 \\
29.1 \\
34.5 \\
5.2\end{array}$ & $\begin{array}{r}116.2 \\
106.0 \\
130.6 \\
124.1 \\
87.9 \\
90.6 \\
118.9 \\
105.4 \\
91.7 \\
79.9 \\
96.1 \\
124.6 \\
106.0 \\
4.8\end{array}$ & $\begin{array}{r}127.4 \\
37.8 \\
66.4 \\
69.2 \\
27.2 \\
79.0 \\
48.2 \\
19.2 \\
43.4 \\
72.4 \\
59.0 \\
9.8\end{array}$ \\
\hline
\end{tabular}

studies on normal human volunteers. ${ }^{18}$

There has been much recent discussion as to the mode of action of beta-adrenoreceptor antagonists on essential tremor, in particular whether effects in the central nervous system are important and also whether there is significant effect via beta- 1 mechanisms either peripheral or central. The present study does however provide support for the contention that the action of beta-adrenoreceptor antagonists on essential tremor is mediated predominantly by peripheral beta- 2 adrenoreceptors. The effective dose of LI 32-468, that is $2 \mathrm{mg}$ has no significant effects on beta- 1 adrenoreceptors as evidenced by the lack of inhibition of standing tachycardia in the patients in this study and in normal volunteers. ${ }^{18}$ It is a markedly hydrophilic compound and therefore has insignificant central effects, particularly when given as a single $2 \mathrm{mg}$ dose in that central accumulation of the drug or an active metabolite could not have occurred. Membrane stabilising activity would not be an important factor in the tremorlytic effect of 2 $\mathrm{mg} \mathrm{LI}$ as in the animal model the membrane stabilising activity of $L I$ is weaker than that of propranolol ${ }^{17}$ and even with propranolol it only becomes significant at plasma levels considerably greater than that which produces beta blockade and attenuation of tremor. ${ }^{2324}$ Furthermore it would be expected that if the membrane stabilising activity was important the higher doses of LI should have been at least equally effective. Thus, a single oral dose of $2 \mathrm{mg} \mathrm{LI}$, a peripherally acting selective beta- 2 adrenoreceptor antagonist was shown to be equipotent, in its effect on tremor magnitude, to $120 \mathrm{mg}$ propranolol. This finding supports the contention of Leigh et al ${ }^{16}$ that the beneficial effects of beta-adrenoreceptor antagonists are mediated predominantly via peripheral beta- 2 adrenoreceptor mechanisms.

These peripheral beta- 2 adrenoreceptors are located on the extrafusal muscle fibres ${ }^{25} 26$ and on 
the intrafusal fibres of the muscle spindles. ${ }^{27-29}$ It has been demonstrated that sympathomimetric amines such as adrenaline will induce tremor or exaggerate essential tremor by a direct effect on these receptors producing both an alteration in muscle contractility 2526 and, more importantly, an increase in muscle spindle sensitivity, ${ }^{30}$ with resulting synchronisation of afferent feedback during the stretch phase of spindle discharge. Such agonist effects can readily be blocked by beta- 2 adrenoreceptor antagonist activity at these receptor sites, though it has not been proved that these are necessarily the only peripheral sites of action of these drugs in essential tremor. ${ }^{31}$ Since the beneficial effect of beta-adrenoreceptor antagonists on essential tremor is peripherally determined, it would be unlikely that complete attenuation of a centrally "driven" tremor could be achieved. Indeed, complete abolition of essential tremor by these drugs is rarely found clinically or in trials employing objective measurement techniques. ${ }^{153435}$ In contrast complete attenuation of large amplitude, low frequency (therefore centrally determined) essential tremor $^{19}$ can be seen using drugs (for example primidone) whose primary action is in the central nervous system. ${ }^{32}$

In the present study there was no correlation between either plasma LI or propranolol levels and reduction in tremor amplitude. This lack of correlation has been a consistent finding in studies of the effect of propranolol on essential tremor. ${ }^{33}{ }^{34}$ This may reflect marked inter-patient differences in the severity and responsiveness of tremor, ${ }^{15}$ the degree of protein binding ${ }^{36}$ the presence of active metabolite(s) or that the drug levels achieved were above that in which any relationship between plasma level and response exists.

Single dose studies of the effects of betaadrenoreceptor antagonists in essential tremor do not always predict the effects of the drug when given on prolonged administration,,$^{35}$ therefore it is necessary to follow up these initial findings with a controlled study to determine whether the effect of the drug is maintained in chronic use. If the response of tremor to small doses of LI is maintained on prolonged administration then this drug may provide a useful addition to drugs currently available for the management of essential tremor. In situations where simultaneous beta- 1 and beta- 2 antagonism may be disadvantageous to the patient with essential tremor, such as in the elderly or in patients with heart disease, there may be an indication to use $\mathrm{LI}$ in preference to propranolol. In other tremulous states such as drug withdrawal, or drug intoxication, there may also be a preference for a beta- 2 adrenoreceptor antagonist. Long-term studies will be necessary to determine whether this drug is better tolerated in patients with essential tremor than propranolol.

\section{References}

' Murray TJ. Essential Tremor. In: Barbeau A, ed. Disorders of Movement Lancaster, MTP Press, 1981:151-70.

${ }^{2}$ Marsden CD. The mechanisms of physiological tremor and their significance to pathological tremors. In: Desmedt JE, ed. Progress in Clinical Neurophysiology. Basel: Karger, 1978;5:1-16.

${ }^{3}$ Winkler GF, Young RR. Efficacy of chronic propranolol therapy in action tremors of the familial, senile or essential varieties. $N$ Engl J Med 1974;290:984-88.

${ }^{4}$ McAllister RJ Jr, Markesbury WR, Ware RW, Howell SM. Suppression of essential tremor by propranolol: correlation of effect with drug plasma levels and intensity of beta-adrenergic blockade. Ann Neurol 1977; 1:160-6.

$s$ Tolosa ES, Lowenson RB. Essential tremor: treatment with propranolol. Neurology (Minneap.) 1975;25:1041-44.

${ }^{6}$ Morgan MH, Hewer RL, Cooper R. Effect of the betaadrenergic blocking agent, propranolol, on essential tremor. J Neurol Neurosurg Psychiatry 1973;36:618-24.

${ }^{7}$ Jefferson D, Jenner P, Marsden CD. Beta-adrenoceptor antagonists in essential tremor. J Neurol Neurosurg Psychiatry 1979;42:904-49.

${ }^{8}$ Dietrichson P, Espen E. Effects of timolol and atenolol on benign essential tremor, placebo controlled studies based on quantitative tremor recording. J Neurol Neurosurg Psychiatry 1981;44:677-83.

9 Young RP, Growden JH, Shahani BT. Beta-adrenergic mechanisms in action tremor. $N$ Engl $J$ Med 1975;293:950-3.

${ }^{10}$ Ljung $O$. Treatment of essential tremor with metoprolol. N Engl J Med 1979;301:1005.

" Britt CW, Peters BH. Metoprolol in essential tremor. $N$ Engl J Med 1979;301:331.

${ }^{12}$ Riley R, Pleet AB. Metoprolol tartrate for essential tremor. $N$ Engl J Med 1979;301:663.

${ }^{13}$ Newman RP, Jacobs L. Metoprolol in essential tremor. Arch Neurol 1980;37:596-597.

14 Turnbull DN, Shaw DA. Metoprolol in essential tremor. Lancet 1980;1:95.

${ }^{15}$ Calzetti S, Findley LJ, Gresty MA, Perucca E, Richens A. Metoprolol and propranolol in essential tremor: a double blind controlled study. J Neurol Neurosurg Psychiatry 1981;44:814-9.

${ }^{16}$ Leigh PN, Jefferson D, Twomey A, Marsden CD. Betaadrenoreceptor mechanisms in essential tremor; a double-blind placebo controlled trial of metoprolol, sotalol and atenolol. J Neurol Neurosurg Psychiatry 1983;46:710-5.

17 Engel G. LI 32-468: Pharmacological Data. Sandoz Ltd. Pharmaceutical Division, Research and Development, 1980.

${ }^{18}$ Aellig WH. LI 32-468: Studies in Healthy Volunteers. 
Sandoz Ltd. Pharmaceutical Division, Research and Development, 1983.

${ }^{19}$ Marsden CD, Obeso J, Rothwell JC. Benign essential tremor is not a single entity. In: Yahr MD, ed. Current Concepts in Parkinson's Disease. Amsterdam: Excerpta Medica, 1983.

${ }^{20}$ Hewlett-Packard. Digital Signal Analyser: User's Guide. HP 05420-900, 1978.

${ }^{21}$ Rosenthaler J, Munzer H. Radio Receptor Assay of LI 32-468. Sandoz Ltd. Pharmaceutical Division, Research and Development, 1983.

${ }^{22}$ Walle T. GLC determination of propranolol, other beta-blocking drugs and metabolites in biological fluids and tissues. J Pharm Sci 1974;63:1885-91.

${ }^{23}$ Coltart DJ, Meldrum SJ. The effect of racemic propranolol, dextropropranolol and racemic practolol on the human and canine transmembrane action potentials. Arch Intern Pharmacodynamics 1971;192:18897.

${ }^{24}$ Larsen A. Effects of pindolol, sotalol and the optical isomers of propranolol on muscle action potentials and depolarising-secretion coupling in the rat. $\mathrm{Act}$ Physiol Scand 1978;102:357-63.

${ }^{25}$ Bowman WC, Nott MW. Actions of sympathomimetic amines and their antagonists on skeletal muscle. Pharmacol Rev 1969;21:27-72.

${ }^{26}$ Marsden CD, Meadows JC. The effects of adrenaline on the contraction of human muscle. J Physiol (Lond) 1970;207:429-448.

${ }^{27}$ Calma I, Kidd GL. The effect of adrenaline on muscle spindles in cat. Arch Italiennes de Biologie 1962;100:381-93.
${ }^{28}$ Smith CM. Neuromuscular pharmacology, drugs and muscle spindles. Ann Rev Pharmacol 1963;3:223-42.

${ }^{29}$ Paintal AS. Effects of drugs on vertebrate mechanoreceptors. Pharmacol Rev 1964;16:341-380.

${ }^{30}$ Young RR, Hagbarth K. Physiological tremor enhanced by manoeuvres affecting the segmental stretch reflex. J Neurol Neurosurg Psychiatry 1980;43:248-56.

${ }^{31}$ Abila B, Marshall RW, Wilson JF, Richens A. Do betaadrenoreceptor blockers have peripheral or central effect in essential tremor. Br J Clin Pharmacol. In press.

${ }^{32}$ Findley LJ, Calzetti S. Primidone in essential tremor. In: Findley LJ, Capiledo R. eds. Movement Disorders Tremor. Macmillan Press (in press).

${ }^{33}$ Jefferson D, Jenner P, Marsden CD. Relationship between plasma propranolol concentration and relief of essential tremor. J Neurol Neurosurg Psychiatry 1979;42:831-7.

${ }^{34}$ Calzetti S, Findley LJ, Gresty MA, Perucca E, Richens A. Effect of a single oral dose of propranolol on essential tremor: a double-blind controlled study. Ann Neurol 1983;13:165-71.

${ }^{35}$ Calzetti S, Findley LJ, Perucca E, Richens A. Controlled study of metoprolol and propranolol during prolonged administration in patients with essential tremor. $J$ Neurol Neurosurg Psychiatry 1982;45:893-7.

${ }^{36}$ Evans GH, Nies AS, Shand DG. The disposition of propranolol. III. Decreased half-life and volume of distribution as a result of plasma binding in man, monkey, dog and rat. J Pharmacol Exp Ther 1973; 186:114-22. 